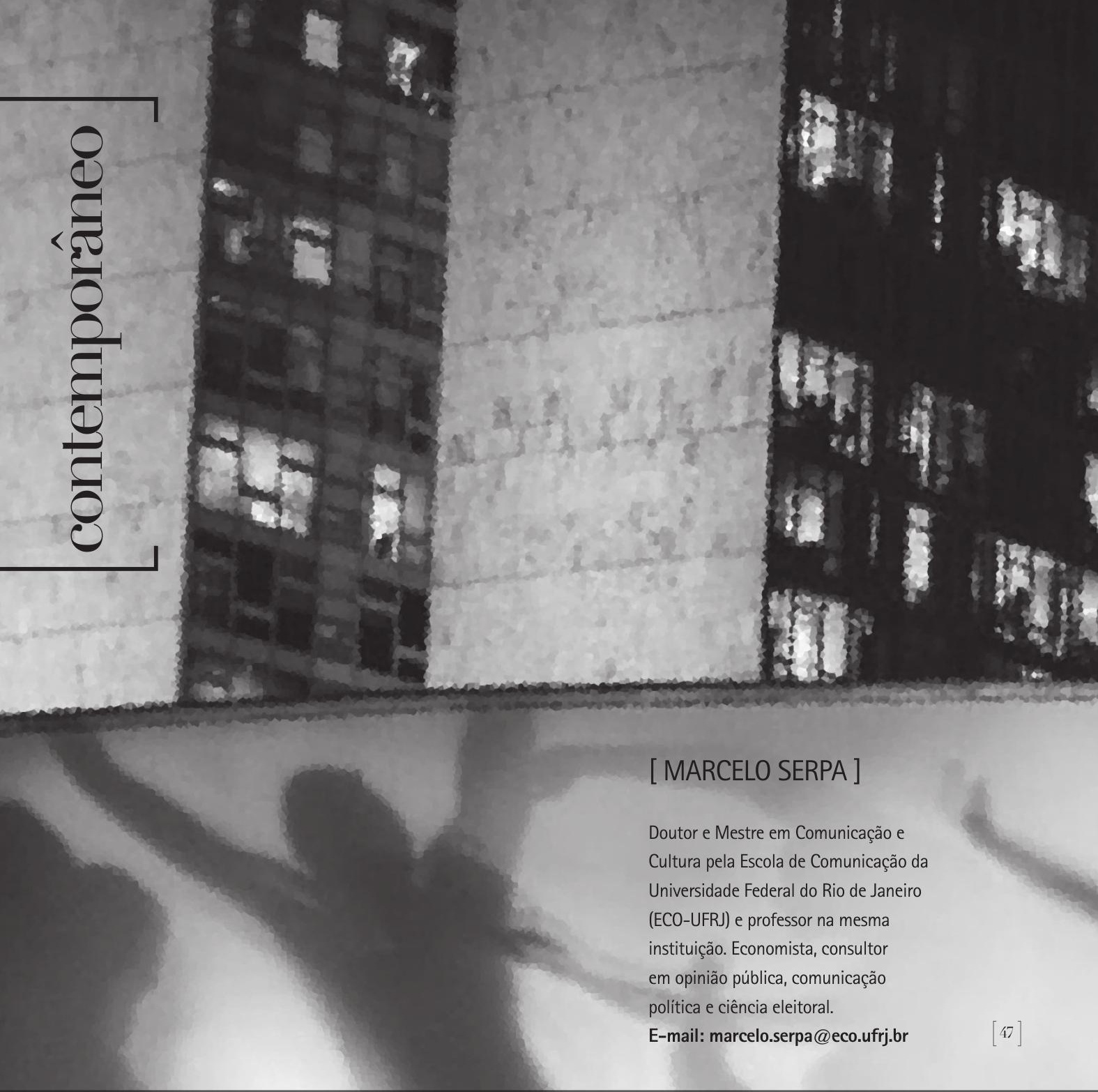

\title{
Manifestações políticas: ocorrências no Brasil e no mundo
}

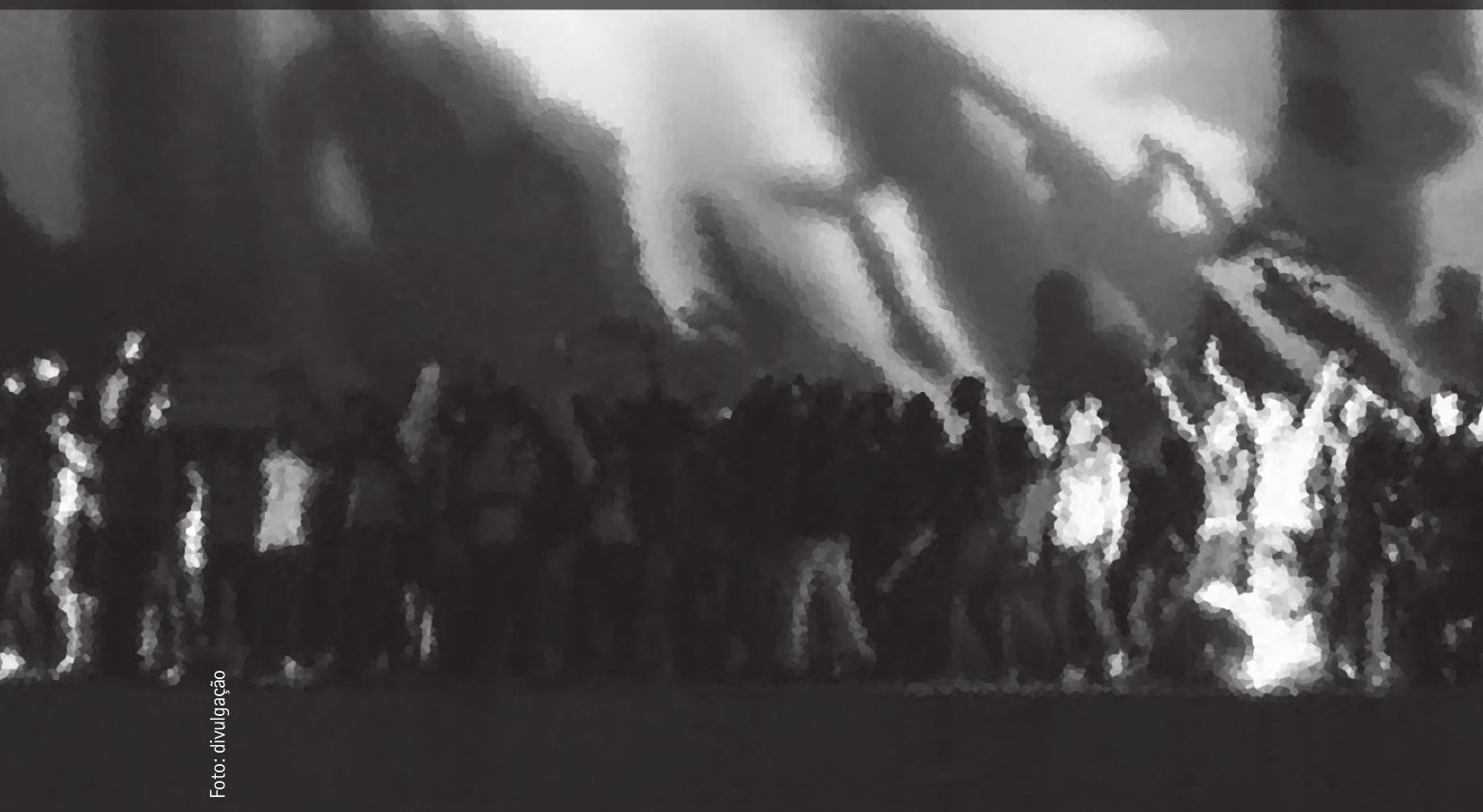


É desconfortável assistir à estranheza e surpresa de muitos perante os acontecimentos recentes de 2013. Mas foi nos corredores e salas (e containers) de aula do Campus Praia Vermelha da Universidade Federal do Rio de Janeiro (UFRJ) que me dei conta de que muitos dos que se assombravam não dispunham de um quadro completo das grandes manifestações políticas populares brasileiras das últimas décadas. Aí estava a explicação para perplexidades e incompreensões: a geração de alunos que ocupa as nossas salas de aula e dos jovens que protestam nas ruas nasceu nos anos 1990. Numa das minhas aulas de Comunicação Política-Eleitoral, ao referir-me muito naturalmente aos "caras pintadas", chamou-me atenção um dos alunos, alertando-me quanto ao fato de que muitos ali não tinham a exata dimensão do que se passara, levando-me inclusive a reformular minha exposição a fim de obter maior compreensão de todos, sobre o nosso "batimento cardíaco político" contemporâneo. Melhor assim.

Então, começaram a "pipocar" dezenas de posts (no mundo digital) da mesma natureza que os comentários (do mundo real) manifestando as mesmas estranhezas e surpresas dos corredores da Universidade, sobre os protestos políticos populares brasileiros a que presensiávamos. Igualmente, despertou minha atenção o tom da crônica de Arnaldo Jabor, não só pela intensidade de perplexidade, mas também pela carga de indignação manifestada em crítica a "esses revoltosos de classe média".

Mas afinal, o que é que provoca um ódio tão violento contra a cidade? (...) Não pode ser por causa de vinte centavos. A grande maioria dos manifestantes são filhos de classe média, isso é visivel: ali não havia pobres que precisassem daqueles vinténs, não! Os mais pobres ali eram os policiais apedrejados, ameaçados com coquetéis molotov, que ganham muito mal. No fundo, tudo é uma imensa ignorância política, é burrice misturada a um rancor sem rumo. Talvez a influência da luta na Turquia, justa e importante contra o islamismo fanático. Mas aqui, se vingam de que? Justamente, a causa deve ser a ausência de causas. Ninguém sabe mais porque lutar, em um país paralisado por uma disputa eleitoral para daqui a um ano e meio. 0 Governo diz que tá tudo bem (...). Por que não lutam contra o projeto de emenda constitucional 37 ? (...) Talvez eles nem saibam o que é a PEC 37, a lei da impunidade eterna. Estes caras vivem no passado de uma ilusão. Eles são a caricatura violenta da caricatura de um socialismo dos anos cinquenta que a velha esquerda ainda defende aqui. Realmente, esses revoltosos de classe média não valem nem $\mathrm{R} \$ 0,20$ (JABOR, 2013).

Mais bem humorado era o comentário do advogado, comunicador e estudioso de ciência política Paulo Senra Breitschaft, que fez considerações interessantes (e divertidas) sobre as manifestações no Rio de Janeiro.

Cansei dessa revolução Peter Pan: só a turma do Capitão Gancho tem objetivo - vandalizar e destruir! Enquanto isso os meninos perdidos da Terra do Nunca e a terceira idade do Ano que Nunca Acabou, ficam brincando de revolucionário, sem respeitar o direito de ir e vir dos outros. Quando complicar vão pedir socorro para o crocodilo (BREITSCHAFT, 2013).

Interessante é que o conceito "Peter Pan" andava mesmo há algum tempo circulando pela internet: os kidults (kid + adults nos Estados Unidos), os "adultecentes" (adultos + adolescentes em Portugal e na América Latina), os "trintões" (com "síndrome de Peter Pan", na Espanha), os da Geração X (como se referem os especialistas de marketing) - basta uma consulta ao Google pelo termo "Geração Peter Pan" para conferir a referência, em dezenas de páginas. Até o The New York Times mencionou que Harry Porter é o Peter Pan da geração que está terminando a faculdade.

0 sexto filme da série foi lançado quase doze anos após o livro que deu início à série: "Harry Potter and the Sorcerer's Stone" ("Harry Potter e a Pedra Filosofal"). Os membros da geração que criou a "pottermania" 
como leitores pré-adolescentes estão se aproximando da formatura na faculdade ou ingressando no mercado de trabalho, e eles têm mantido acesa essa chama da sua adolescência (BROWNE, 2009).

Mas o uso político da metáfora do professor Breitschaft surgiu novamente, dessa vez nas páginas da versão digital da Revista da Cultura, em artigo assinado por Ulisses Tavares.

A geração a que me refiro, infelizmente, não é essa, atual, que rouba e mata sem noção. É a minha, aquela que, quando jovem, acreditou em muitas tolices bem intencionadas. 0 Partido dos Trabalhadores (...), o Partido Verde (...), o MDB (...), o Estatuto da Criança e do Adolescente (...) que se tornou um aval para a bandidagem mirim. (...) Feministas (...). Está mais que na hora de minha geração crescer, fazer mea culpa, ou culpa inteira, e dar a volta por cima, saindo debaixo dessa cumplicidade indecente (TAVARES, 2013).

É interessante perceber a aplicação de uma mesma metáfora a duas gerações, de certa forma tão diferentes, e isso me faz pensar se não seria, talvez, porque o que é saliente na verdade é a percepção de certa alienação política presente em muitas gerações distintas, o que o saudoso professor Cid Pacheco descrevia como Lei da Indiferença, que versa sobre a normalidade dos quadros eleitorais marcados por pequenas minorias (politizadas) pró e contra e grandes maiorias despreocupadas que com 0 avançar da eleição migram para uma das outras posições, diminuindo a indiferença num processo escalonado, que primeiro vai da indiferença à indefinição, depois à indecisão, em seguida à simpatia, para finalmente chegar a alguma adesão moderada o que prevalece é o centro moderado e não os extremos estridentes, a maioria discreta e silenciosa, somente acessada artificialmente por pesquisas de opinião qualitativas e quantitativas (SERPA, 2013).

Então, vejamos as manifestações e os protestos brasileiros já considerados históricos que as maiorias parecem olvidar, seja por não os terem vivenciado, como no caso das gerações mais novas, seja por não atentarem a eles, como é o caso dos indiferentes. Vou ater-me aqui a somente aqueles que ajudaram a escrever o processo de redemocratização do Brasil, no final do século passado - "Diretas já" e "Impeachment de Collor".

Em 1979, o regime militar aprovou medidas de abertura às liberdades democráticas no Brasil, como a substituição do sistema bipartidário por um multipartidarismo que abriu espaço para a formação de novos partidos que, ao mesmo tempo, representavam maior direito de expressão política e também marcaram um processo de fragmentação político-partidária. Já em 1982, os novos partidos disputavam eleições estaduais no Executivo e Legislativo. Posteriormente, a Câmara dos Deputados articulou uma lei que instituiu o voto direto na escolha do sucessor do presidente militar General João Batista Figueiredo. A iniciativa tomou forma de projeto de lei em 1983, a Emenda Dante de Oliveira, que repercutiu nas capitais e grandes cidades do país, e membros dos partidos de oposição, como PMDB, PT e PDT, passaram a organizar grandes comícios apoiados pela população favorável à escolha direta para o cargo de Presidente, atos que se transformaram no movimento "Diretas Já!" - uma das maiores manifestações populares já ocorridas no país, marcada por comícios liderados por políticos, entre os quais encontravam-se figuras perseguidas pela ditadura militar, membros da classe artística, intelectuais que militavam pela aprovação do projeto de lei.

Vejamos alguns números das dezenas de comícios organizados nas principais cidades brasileiras - em janeiro de 1984, 300 mil pessoas na Praça da Sé, em São Paulo; um milhão de cidadãos na Candelária, no Rio de Janeiro; 1,7 milhão de pessoas em São Paulo, no Vale do Anhangabaú; 250 mil pessoas em Belo Horizonte. Percalços: afastamentos dos governadores de São Paulo, Rio de Janeiro e Minas Gerais dos comícios e sabotadores que chegaram a jogar pó químico durante comício em Anápolis, em Goiás. Resultado: por uma diferença de apenas 22 votos e um vertiginoso número de abstenções, a Emenda Dante de Oliveira, que previa a eleição presidencial por voto popular, não passou, e o Brasil manteve o sistema indireto para as eleições de 1985. A oposição conseguiu eleger, por via indireta, Tancredo Neves - que morreu antes de tomar posse e foi substituído por José Sarney, ex-membro do partido do regime militar (CARNEIRO, 2013). 
Somente em 1989 os brasileiros puderam eleger seu presidente, participando como nunca da campanha eleitoral, numa gigantesca mobilização nacional. A disputa final se deu em segundo turno entre Fernando Collor de Mello e Luiz Inácio Lula da Silva, e, após três décadas, Collor foi eleito presidente pelo voto direto. Instalado o novo governo, o mais traumático dos planos econômicos - Plano Collor - confiscou a poupança e a conta corrente dos brasileiros com a justificativa de acabar com a inflação brasileira. Seguiram-se fracassos econômicos, trapalhadas políticas, denúncias familiares e ao governo, esquemas de poder paralelo...

Em 1992, a população foi novamente às ruas pedir a saída do presidente; Congresso e Judiciário colocaram-se à caça de Collor, que, no final de setembro daquele ano, se tornou o primeiro presidente da história política brasileira a sofrer um processo de impeachment. No início de outubro, o casal Rosane e Fernando Collor, vaiados em meio a multidão, "desceu a rampa" e deixou o Planalto. Em dezembro, Collor renunciou para evitar o impeachment, momentos antes de o Senado julgá-lo culpado, caçando-lhe o mandato e os direitos políticos até o ano 2000. Vale lembrar que, em Miami, Collor permaneceu em silêncio até outubro de 1997, quando voltou ao Brasil para o julgamento do recurso no Supremo Tribunal Federal. Em fevereiro do ano seguinte, o Conselho do Contribuinte, em Brasília, anunciou que Collor havia sido liberado do pagamento de quatro milhões de reais em impostos cobrados pela Receita Federal, mas restou uma multa de um milhão (CARNEIRO, 2013).

Mas o que há de novo nos movimentos populares deste século com relação às manifestações do século passado? Nas do século passado, eram manifestações de rua, de massas mobilizadas por iniciativa de forças políticas organizadas, em torno de motivações específicas e/ou pontuais. Os protestos atuais são, do mesmo modo, manifestos de rua, de massas movidas por iniciativa de grupos, mais que segmentados, fragmentados, em torno de motivações igualmente segmentadas ou fragmentadas, que aparentemente rejeitam lideranças políticas, e organizam-se por meio das mídias sociais, menos significativas no passado. A propósito, com formatação mais global, ou seja, modus operandis e ocorrências mais ou menos universais.

Como lembra Padilha (2013), Norberto Bobbio (1986) já propunha uma reflexão à conjugação de democracia, bem-estar social, liberdade e justiça social. Hoje, cidadãos do mundo ocidental buscam diretamente, por intermédio das manifestações nas ruas, o protagonismo da definição das ações estatais que correspondam às suas prioridades, numa tentativa de exercício de liberdade pela justiça social.

Padilha (2013) acrescenta que as democracias representativas, conjugadas às democracias participativas legitimamente constituídas, não correspondem às aspirações da população, seja na França, na Espanha, nos Estados Unidos, na Turquia, no Egito, no Chile, e agora no Brasil... Uma das possíveis explicações seria que, com a participação de todos pelas mídias sociais, onde todos interagem entre si, a cidadania estaria dando passos largos rumo à democracia direta.

Os movimentos que ganham nossas ruas, não são conduzidos por líderes, por partidos políticos ou pelo interesse na tomada do poder. Seu combustível é uma causa justa. 0 que a cidadania digital exige é que 0 exercício do poder estatal seja norteado pela eficiência (...), pela ética e pela sintonia fina com suas efetivas prioridades (...). As manifestações vieram para ficar. Simbolizam um novo estágio da cidadania. A vida em sociedade atingiu novos patamares. As conquistas da cidadania não serão renunciadas. Haverá variação nos temas, mas elas continuarão. A civilização do conhecimento e a globalização digital em que nos encontramos, viabilizam o protagonismo direto do cidadão nas ações estatais rotuladas como de seu interesse, especialmente nas relativas aos serviços públicos. 0 desafio é o de ler e interpretar corretamente o sentimento dos manifestantes (PADILHA, 2013).

Tomando outro aspecto relevante, o das minorias, o advogado, escritor e diplomata Alexandre Vidal Porto, com brilhantismo demonstra a complexidade das questões que envolvem o tema. 
0 nivel da proteção estendida às minorias é indicativo da qualidade de um regime democrático. 0 membro de uma minoria, seja ela étnica, política, religiosa ou sexual, tem direitos que não podem ser ameaçados ou suprimidos. Líderes eleitos governam para todos, para os que com eles concordem ou não. Achar que as urnas asseguram o direito de ignorar os eleitores derrotados é autoritário. Trata-se de visão simplista, convenientemente deturpada, que considera a existência de eleições fator suficiente para conferir caráter democrático a um regime político. Acontece que, para o verdadeiro exercício da democracia, eleições são só o começo. É preciso, também, respeito a uma ordem constitucional pluralista, imprensa e instituições livres, e sistema judiciário que aplique a lei com equidade. Sobretudo, democracia pressupõe garantia aos direitos individuais. Sem isso, não adianta querer posar de democrático (PORTO, 2013).

Porto também relata a intransigência que inviabilizou o governo de Mohamed Mursi e aleijou a democracia egípcia.

Lideres eleitos com instintos autoritários parecem acreditar que a vitória alcançada nas urnas lhes confere permissão para suprimir direitos aos que a eles se opõem. Com o objetivo de se eternizarem no poder, destroem o próprio sistema que os habilitou a governar. Democracia que não admite dissenso é só uma tirania eleita (PORTO, 2013).

Mas, voltando à surpresa, e até indignação, perante as aparentes indefinições das motivações dos movimentos brasileiros atuais, como se explica a ausência de um fato gerador único, ou de lideranças não identificadas? Parece que a resposta está associada ao processo de construção de identidade e à teoria do consumo.

Segundo Maria Lucia Bueno, o sociólogo Colin Campbell observa que no século XXI as pessoas são cada vez mais identificadas por seus desejos e preferências, que se traduzem nos chamados gostos pessoais. Entretanto, Bueno pondera, "a satisfação das carências e a acumulação não são as bases do consumo hedonista moderno, em que 0 anseio pelo objeto pode trazer um prazer maior e mais intenso do que a efetivação da sua posse". E acrescenta: "Essa insatisfação permanente seria a matriz do caráter insaciável do consumismo" (BUENO, 2013, p. 22).

Gilles Lipovetsky vai ao encontro das considerações de Campbell ao abordar o tema da "sociedade da decepção". Em entrevista a Cláudio Diniz, ele destaca:

A decepção não é um fenômeno próprio só de nossa sociedade, ela acompanha a condição humana. As sociedades modernas individualistas possibilitaram um sonho de uma felicidade crescente para todos. A democracia abriu caminho para o mito da felicidade coletiva. A sociedade de consumo propõe, incessantemente, novos desejos. Podemos e queremos cada vez mais. (...) Agora sofremos por não ter nossos desejos satisfeitos e não compreendemos por que não somos felizes. Não conseguimos alcançar tudo. A vida privada se tornou muito complicada. (...) E a globalização cria condições intensas de competição, exigências (LIPOVETSKY, 2013, p. 133).

Parece mesmo que esse sentimento, a insatisfação, é intrínseco à sociedade contemporânea. Nicolás Maduro, presidente da Venezuela, em discurso recente, também mencionou a seus ministros sobre o consumo capitalista. 
0 consumismo capitalista, companheiros, nos leva (sempre nos vai levar, sempre) à insatisfação do ser humano. (...) Isso vem sendo estudado, há um conjunto de especialistas estudando os fenômenos que se estão presentes nas sociedades onde atuam governos progressistas e revolucionários. Falam do fenômeno da insatisfação produto do capitalismo consumista (...). A única verdadeira superação dos antivalores do capitalismo consumista é construir os valores da vida em felicidade, dos conceitos da felicidade social (MADURO, 2013, tradução nossa).

Diante do que foi dito, podemos arriscar um diagnóstico: estamos diante da manifestação de uma nova sociedade da insatisfação munida de uma poderosa ferramenta de comunicação - as redes sociais. Explorar o potencial e maximizar a utilização dessa nova mídia e das interações sociais que esta possibilita pode ser vital para uma nova prática política e aprimoramento do exercício da cidadania.

\section{REFERÊNCIAS}

BOBBIO, N. O futuro da democracia: uma defesa das regras do jogo. Rio de janeiro: Paz e Terra, 1986.

BREITSCHAFT, P. S. Revolução Peter Pan. Disponivel em: <https://www.facebook.com/paulo. breitschaft?fref=ts>. Acesso em: 12 jun. 2013.

BROWNE, D. Harry Potter é o Peter Pan da geração que está terminando a faculdade. The New York Times, 23 jul. 2009. Disponivel em:<http://goo.gl/AYuj5>. Acesso em: 21 jul. 2013.

BUENO, M. L. Por que ler Colin Campbell? dObras, São Paulo: Estação das Letras e Cores, v. 6, n. 13, p. 20-23, maio 2013.

CARNEIRO, R. Enem: protestos históricos no Brasil: Diretas Já, impeachment de Collor e atuais manifestações. Veja, São Paulo, 20 jun. 2013. Disponivel em: <http://veja.abril.com.br/noticia/ educacao/enem-protestos-historicos-no-brasil-diretas-ja-impeachment-de-collor-e-atuaismanifestacoes>. Acesso em: 21 jul. 2013.

JABOR, A. Arnaldo Jabor fala sobre onda de protestos contra aumento nas tarifas de ônibus. Jornal da Globo, 12 jun. 2013. Disponivel em: <http://goo.gl/o3W6H>. Acesso em: 20 jul. 2013.

LIPOVETSKY, G. dObras, São Paulo: Estação das Letras e Cores, v. 6, n. 13, p. 132-135, maio 2013. Entrevista concedida a Cláudio Diniz.

MADURO, N. Reunión con gobernadores, 17 jul. 2013. Disponivel em: <http://youtu.be/ X8JeYQam694>. Acesso em: 21 jul. 2013.

PADILHA, E. Qual Democracia? 18 jul. 2013. Disponivel em: <http://pmdb.org.br/artigos/qualdemocracia>. Acesso em: 21 jul. 2013.

PORTO, A. V. Democracias de mentira. Folha de S.Paulo, 20 jul. 2013. Disponivel em: <http:// www1.folha.uol.com.br/colunas/alexandrevidalporto/ 2013/07/1314043-democracias-de-mentira. shtml>. Acesso em: 21 jul. 2013.

SERPA, M. Eleições espetaculares: como Hugo Chávez conquistou a Venezuela. Rio de Janeiro: Contracapa/Faperj, 2013.

TAVARES, U. A geração Peter Pan precisa crescer. Revista da Cultura, 10 jul. 2013. Disponível em: $<$ http://goo.gl/YSmlD>. Acesso em: 21 jul. 2013. 